\title{
Stirling cycle cryocooler exported vibration analysis
}

\section{Annino Vaccarella, Robert Boz, Robert Sharp, Michael Ellis, Andrew Bish, et al.}

Annino Vaccarella, Robert Boz, Robert Sharp, Michael Ellis, Andrew Bish, David Adams, David Chandler, Luke Gers, James Gilbert, John Hart, Nick Herrald, Mike Petkovic, "Stirling cycle cryocooler exported vibration analysis," Proc. SPIE 10703, Adaptive Optics Systems VI, 107035C (11 July 2018); doi: $10.1117 / 12.2313024$

Event: SPIE Astronomical Telescopes + Instrumentation, 2018, Austin, Texas, United States 


\title{
Stirling Cycle Cryocooler Exported Vibration Analysis
}

\author{
Annino Vaccarella ${ }^{a}$, Robert Boz ${ }^{a}$, Robert Sharp ${ }^{a}$, Michael Ellis ${ }^{a}$, Andrew Bish ${ }^{a}$, David Adams ${ }^{a}$, \\ David Chandler ${ }^{\mathrm{a}}$, Luke Gers ${ }^{\mathrm{a}}$, James Gilbert ${ }^{\mathrm{a}}$, John Hart ${ }^{\mathrm{a}}$, Nick Herrald ${ }^{\mathrm{a}}$, Mike Petkovic ${ }^{\mathrm{a}}$ \\ aAustralian National University, Mt Stromlo Observatory, Weston ACT, Australia, 2611
}

\begin{abstract}
The Australian National University (ANU), we are undertaking to deploy a Lucky Imaging instrument on the $2.3 \mathrm{~m}$ telescope at Siding Springs using a Leonardo SAPHIRA near-infrared electron Avalanche Photo-Diode (eAPD) array, capable of high cadence imaging with frame rates of $10-5,000 \mathrm{~Hz}$ over the wavelength range of $0.8 \mu \mathrm{m}$ to $2.5 \mu \mathrm{m}$. compact cryocooler capable of cooling the Leonardo SAPHRA APD and associated cryogenic electronics to temperatures below $100 \mathrm{~K}$ with little to no vibration. An ideal candidate cryocooler is the Sunpower Cryotel GT with active vibration cancellation. The Cryotel GT is an orientation independent, Stirlng cycle cooler with water jacket heat rejection. This cooler will meet the system cooling requirements. The cryocooler has been integrated with the APD Lucky Imager cryostat through 3 rubber isolating mounts and bellows and tested while suspended from a stable frame. The tethers supporting the cryostat and cooler assembly are not attached to the cryostat and cooler. The exported vibration was measured simultaneously in all 3 axis on the external cryostat wall and internally on the cryostat getter attached directly to the cold tip of the cooler. The test results were collected while the cryocooler was cooling and at the stable set point, at various levels of cooling power and with thermal control enabled and disabled.
\end{abstract}

Keywords: Cryocooler, active damping, Cryotel GT.

\section{INTRODUCTION}

The aim of the test is to measure and characterize the vibration of the cooling system for the APD Lucky Imager and ensure that any vibration emanating from the cryocooler is sufficiently isolated from the internal electronics and the cryostat to telescope interface to mitigate any loss of precision or damage to hardware.

The Cryotel GT is a free piston based Stirling Cycle Cryocooler with active vibration cancellation coupled to an accelerometer attached to the body of the cryocooler. The Cryotel GT tested here was equipped with the optional water jacket to improve heat rejection.

The results from testing the cryocooler vibration will also feed into any proposed designs for cooling GMTIFS.

\section{TEST SETUP}

The cryocooler has been integrated with the APD Lucky Imager cryostat through 3 natural rubber isolating mounts and bellows and tested while suspended from a stable frame. The tethers supporting the cryostat and cooler assembly are not attached to a handling frame to which the cryostat and cooler assembly are connected. 


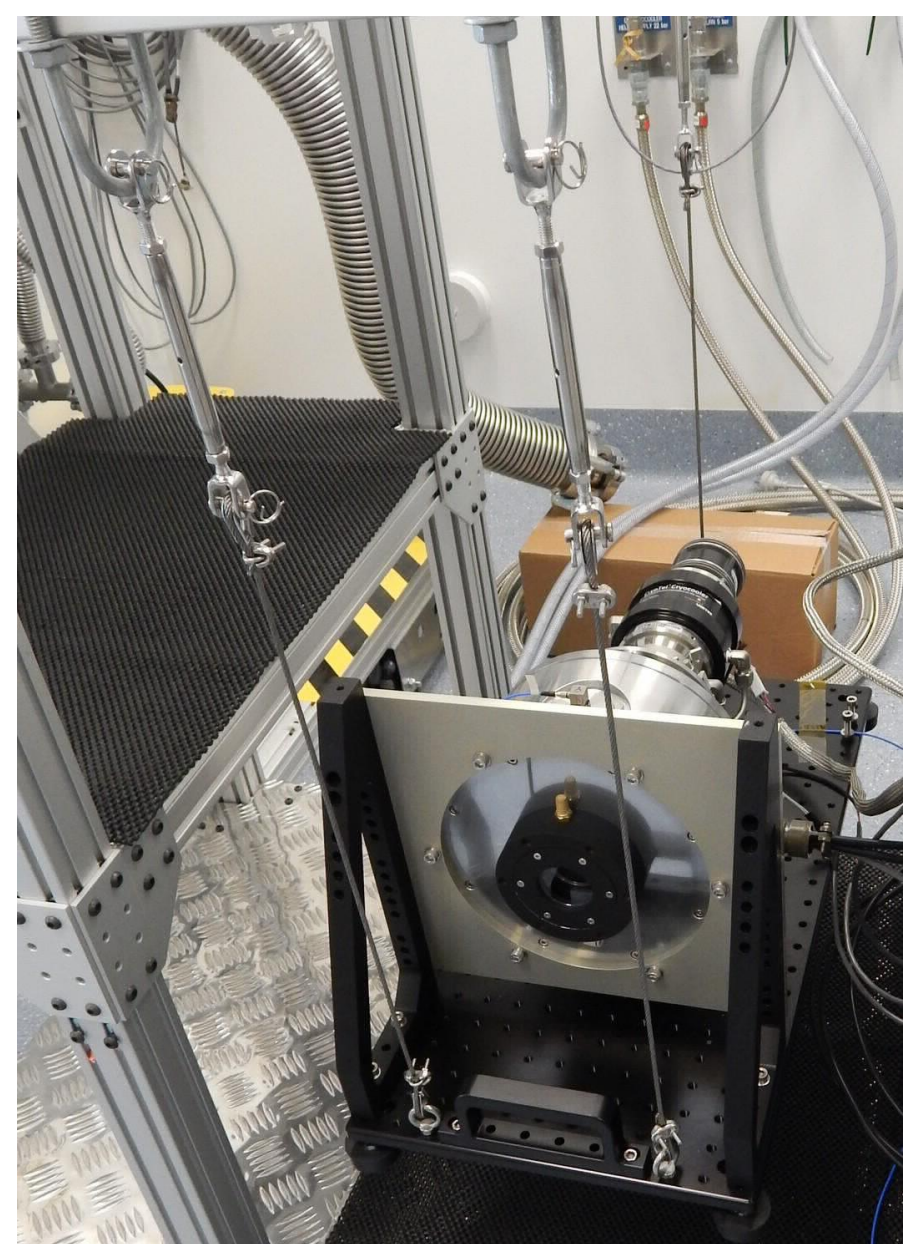

Figure 1. Photo of the assembled cryostat attached to the handling frame and suspended from a rigid frame for vibration testing

The exported vibration was measured simultaneously in all 3 axis on the external cryostat wall and internally on the cryostat getter attached directly to the cold tip of the cooler. The tests were undertaken in a closed room with no air conditioning on a non work day to minimise the impact from other activities within the building.

Accelerometer data was collected in a series of seven tests starting with all systems off gradually progressing to the fully operational system operating at a steady at the set point temperature of $70 \mathrm{~K}$. At a steady $70 \mathrm{~K}$ the cryocooler was operating at 70 watts with a rejection temperature of $21.12^{\circ} \mathrm{C}$. 


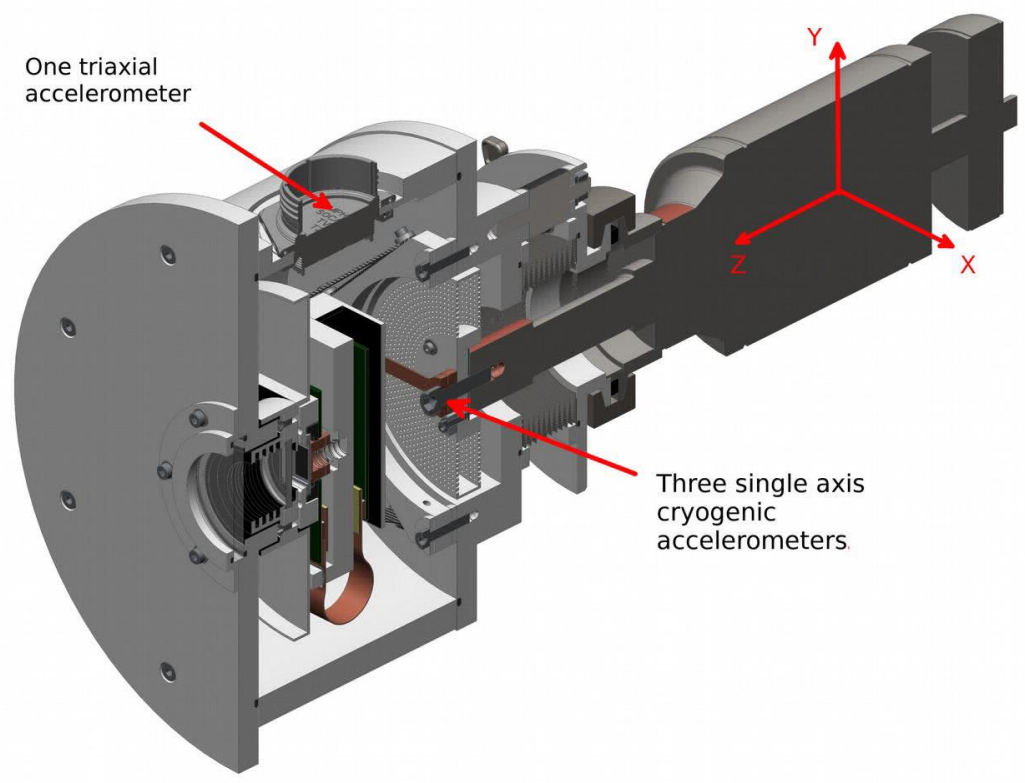

Figure 2: Drawing of the assembled cryostat and cryocooler showing the location of the accelerometers used in testing and the axis of

\section{RESULTS}

The testing with all systems off showed no contribution to the vibration from external sources and only insignificant contributions from connecting the water supply which was quickly swamped by the vibration from the cryocoooler.

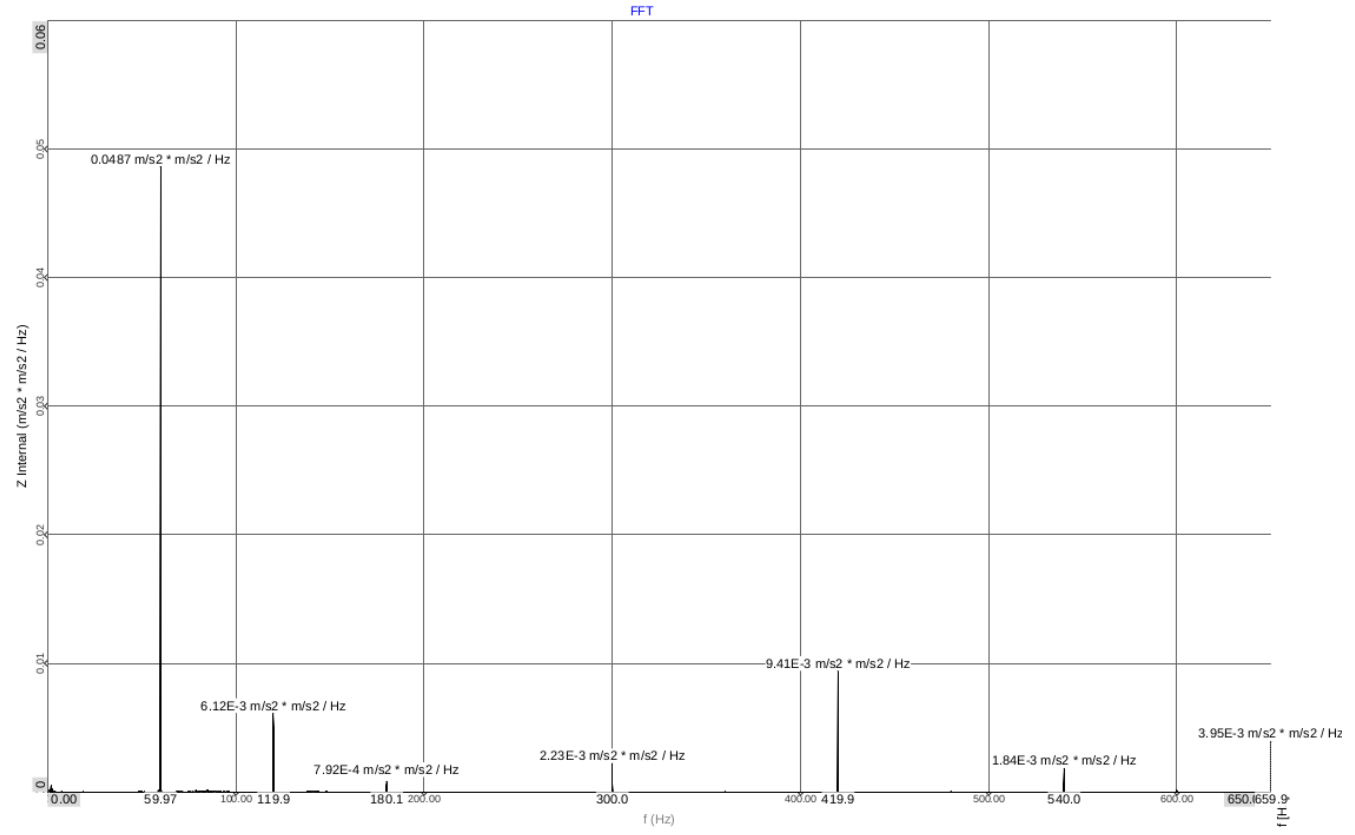

Figure 3: Power spectral density for the vibration measured along the internal $\mathrm{Z}$ axis measured at the cold finger. 


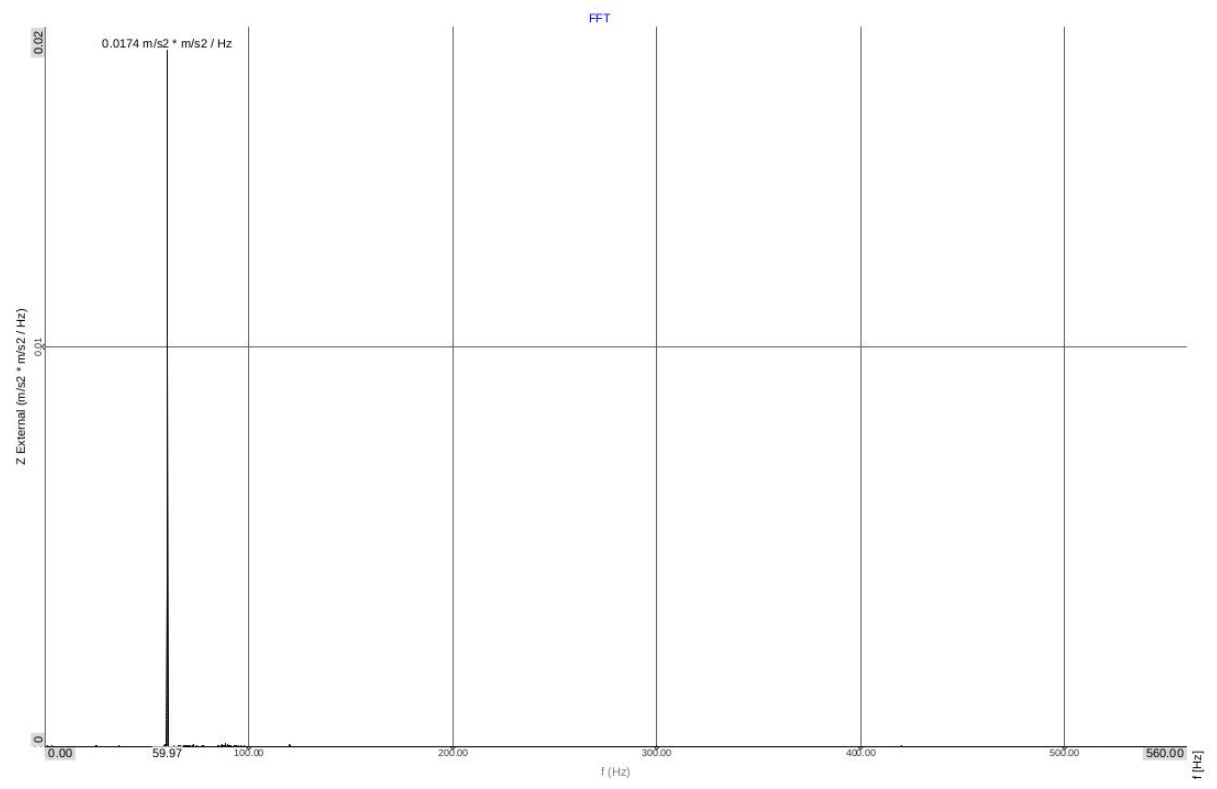

Figure 4: Power spectral density for the vibration measured along the external $\mathrm{Z}$ axis.

The main vibration took place at $60 \mathrm{~Hz}$ and $120 \mathrm{~Hz}$ which is consistent with the operating frequency of the of Cryotel GT cryocooler.

The internal accelerometers also measured vibrations at a range of frequencies extending all the way to $540 \mathrm{~Hz}$ in both the $\mathrm{Z}$ and $\mathrm{Y}$ axes but not the $\mathrm{X}$ axis. The weight of the cryocooler causes it to sag in the $\mathrm{Y}$ axis on the rubber mounts when operating in the horizontal. This sagging of the cryocooler causes some of the vibration in the $\mathrm{Z}$ axis to spread into the $\mathrm{Y}$ axis as seen in figure 5 . The high frequency vibrations measured on the internal accelerometers are not visible in the measurements taken from the external accelerometers. The natural rubber isolators proved very effective at isolating the vibrations at frequencies above $120 \mathrm{~Hz}$. Vibrations at $120 \mathrm{~Hz}$ and below were well attenuated but not completely isolated by the rubber isolators and this is true for all three axis of vibration.

The complete cryostat assembly and stand weigh $18.2 \mathrm{~kg}$ and the peak acceleration measured on each external axis was at $60 \mathrm{~Hz}$. The peak acceleration and force for each external axis is shown in table 1 below.

\begin{tabular}{|c|c|c|}
\hline Axis & $\begin{array}{c}\text { Acceleration } \\
\left(\mathrm{m} / \mathrm{s}^{2} \mathrm{RMS}\right)\end{array}$ & $\begin{array}{c}\text { Force } \\
(\mathrm{N})\end{array}$ \\
\hline $\mathrm{X}$ & 0.163 & 2.97 \\
\hline $\mathrm{Y}$ & 0.023 & 0.42 \\
\hline $\mathrm{Z}$ & 0.0669 & 1.22 \\
\hline
\end{tabular}

Table 1: Force and acceleration measured on each external axis on the cryostat wall. 


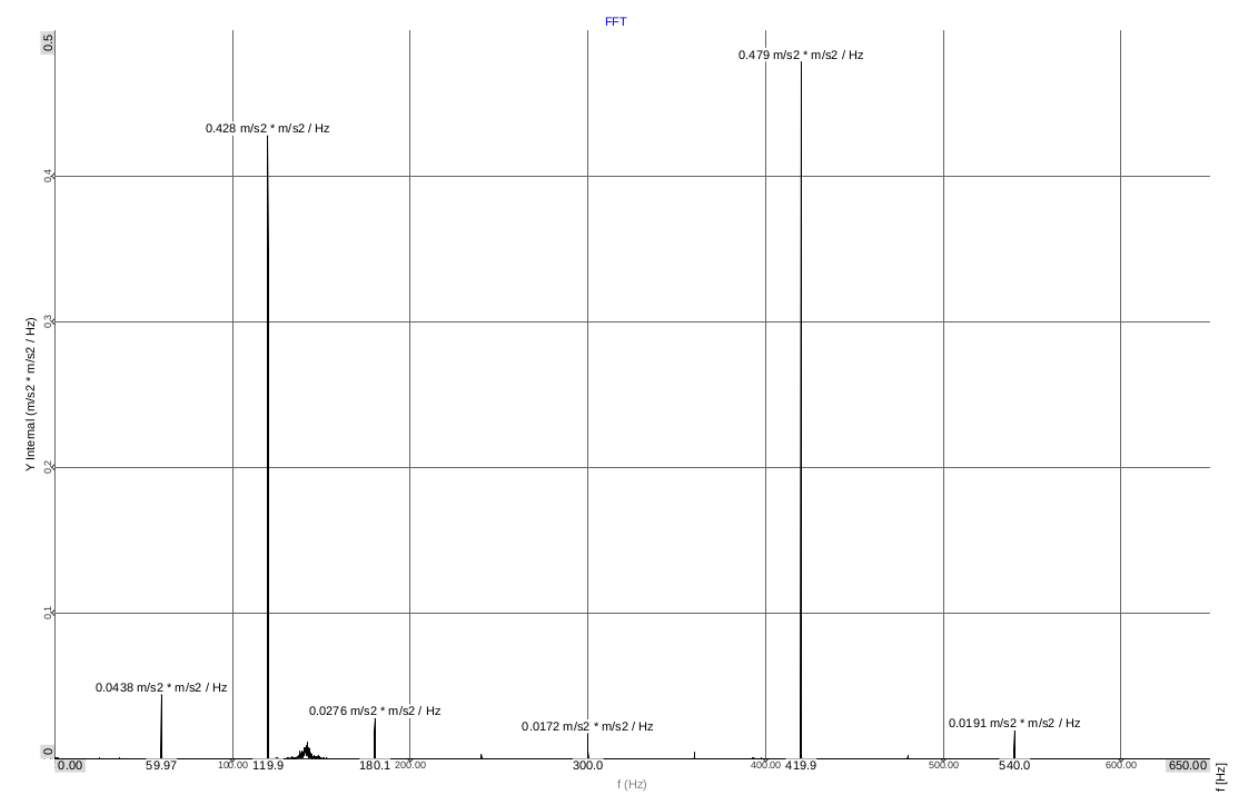

Figure 5: Power spectral density for the vibration measured along the internal Y axis.

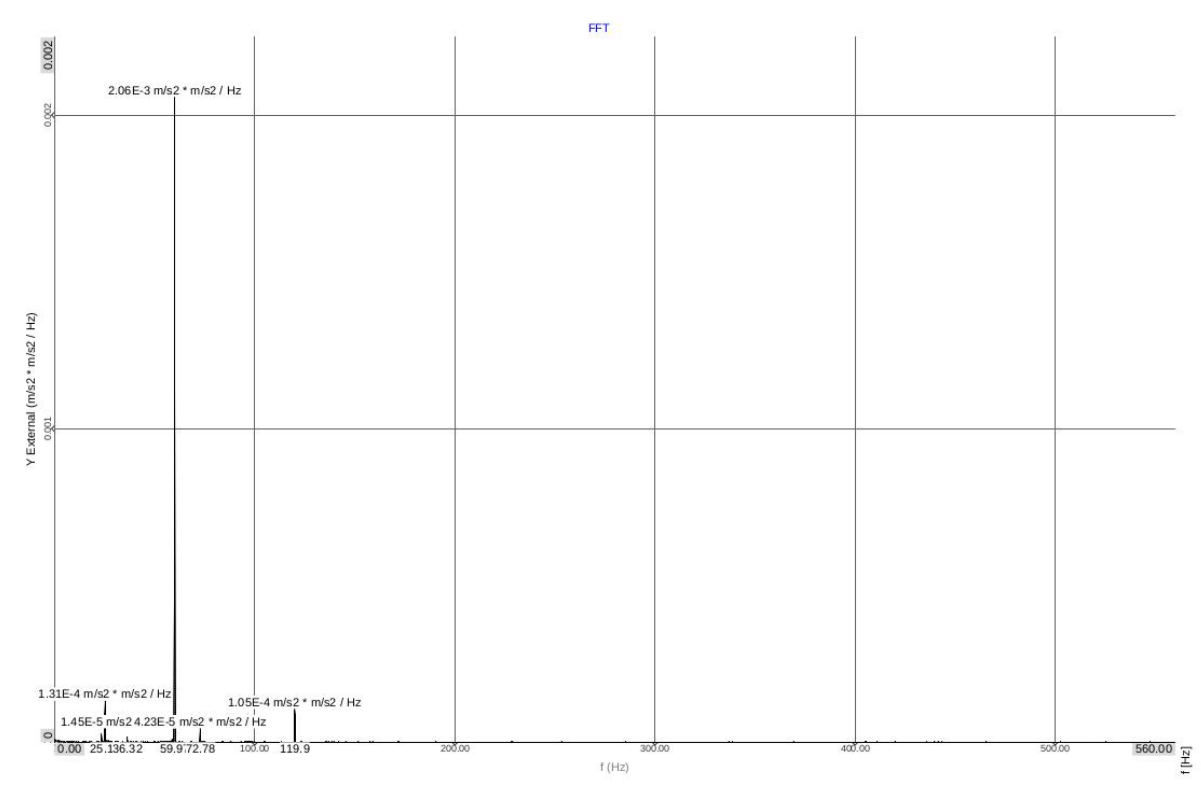

Figure 6: Power spectral density for the vibration measured along the external Y axis.

Proc. of SPIE Vol. 10703 107035C-5

Downloaded From: https://www.spiedigitallibrary.org/conference-proceedings-of-spie on 16 Jul 2019 Terms of Use: https://www.spiedigitallibrary.org/terms-of-use 


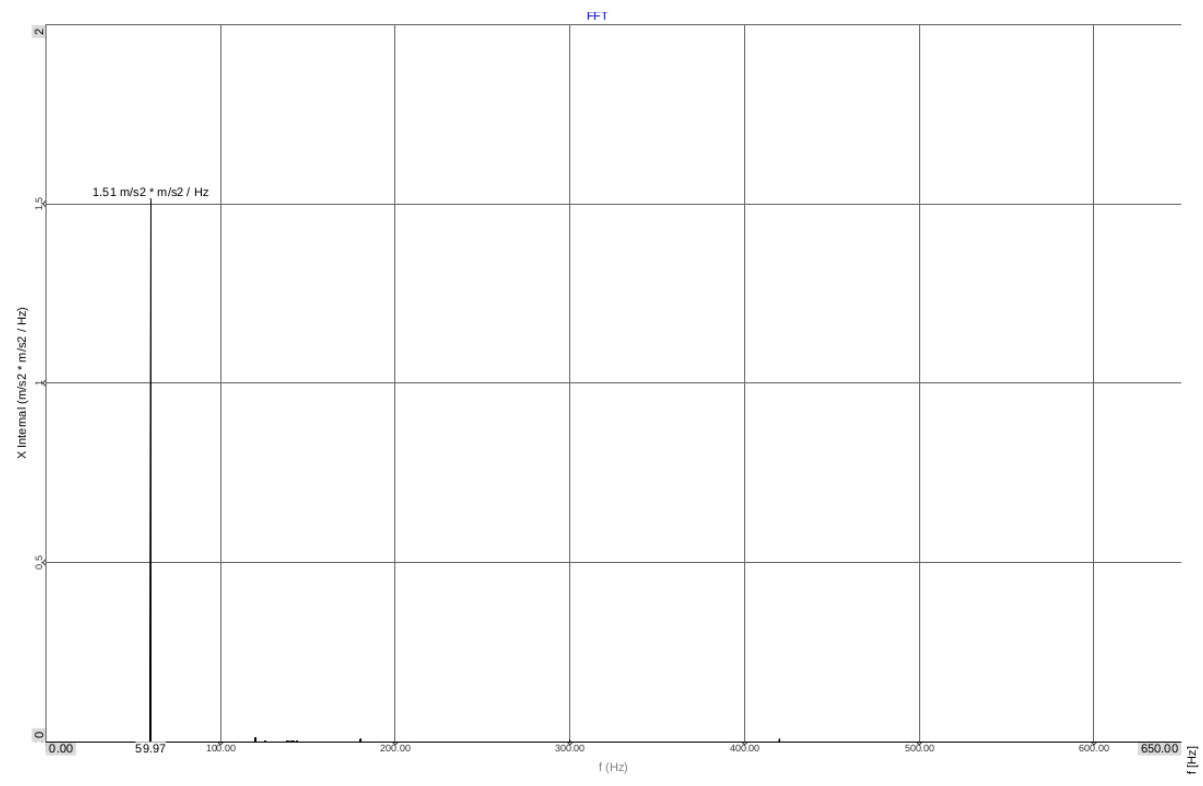

Figure 7: Power spectral density for the vibration measured along the internal $\mathrm{X}$ axis.

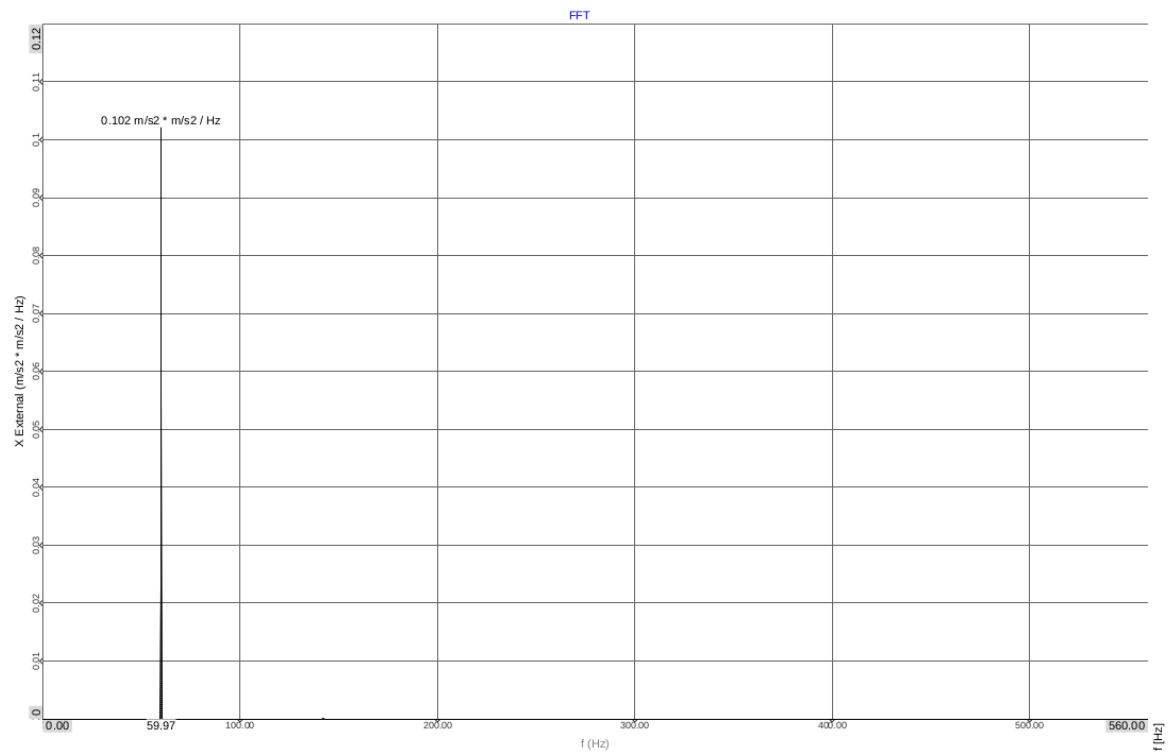

Figure 8: Power spectral density for the vibration measured along the external $\mathrm{X}$ axis.

The external $\mathrm{X}$ axis displayed the greatest level of vibration. It is not clear why the $\mathrm{X}$ axis should experience the greatest vibration when the greatest source of vibration was along the $\mathrm{Z}$ axis. One possibility is that suspending cryostat along the $\mathrm{z}$ axis with slightly opposing cables dampened some of the vibration along the $\mathrm{Z}$ axis. The natural rubber isolators allowed the cryocooler to slant down slightly along the $\mathrm{Y}$ axis. This may also have contributed to some spreading of the vibration from the $\mathrm{Z}$ axis to the $\mathrm{Y}$ axis.

The APD Lucky Imager cryostat is now fully operational and scheduled for first light in October 2018. Below is an image of a lens barrel taken by an engineering grade Leonardo SAPHIRA APD with the cryostat operating cold at a temperature of $80 \mathrm{~K}$. 


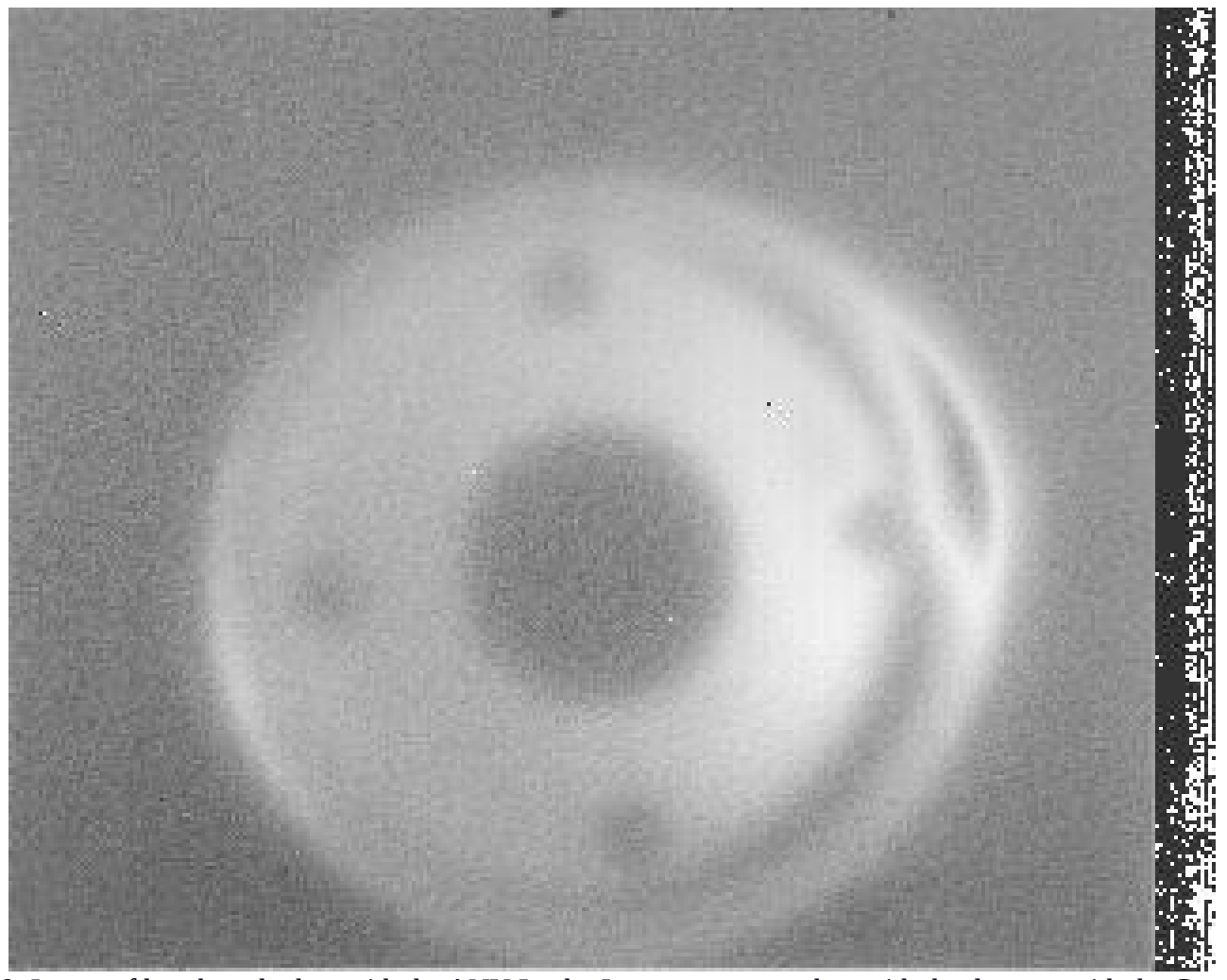

Figure 9: Image of lens barrel taken with the ANU Lucky Imager cryostat taken with the detector with the Cryotel GT maintaining a steady $80 \mathrm{~K}$.

\section{CONCLUSION}

The Cryotel GT has vibration at $60 \mathrm{~Hz}$ and $120 \mathrm{~Hz}$ with the active damping operational. The vibration experienced by the detector and internal electronics is insignificant to image quality. The level of vibration coupled to the cryostat housing and on to the telescope is not expected to cause any damage or image degradation.

\section{REFERENCES}

[1] Installation and Operation Manual for the SunpowerCryotel GT, Revision 7, May 192016.

[2] Gert Raskin et al, “Compact Stirling cooling of astronomical detectors, arXiv:1311.0685 [astro-ph.IM] 